\title{
Interference-Blind Microfluidic Sensor for Ascorbic Acid Determination by UV/vis Spectroscopy
}

Bi, Hongyan; Oliveira Fernandes, Ana Carolina; Cardoso, Susana; Freitas, Paulo

\section{Published in:}

Sensors and Actuators B: Chemical

Link to article, DOI:

10.1016/j.snb.2015.10.072

Publication date:

2016

Document Version

Peer reviewed version

Link back to DTU Orbit

Citation (APA):

$\mathrm{Bi}, \mathrm{H}$., Oliveira Fernandes, A. C., Cardoso, S., \& Freitas, P. (2016). Interference-Blind Microfluidic Sensor for Ascorbic Acid Determination by UV/vis Spectroscopy. Sensors and Actuators B: Chemical, 224, 668-675. https://doi.org/10.1016/j.snb.2015.10.072

\section{General rights}

Copyright and moral rights for the publications made accessible in the public portal are retained by the authors and/or other copyright owners and it is a condition of accessing publications that users recognise and abide by the legal requirements associated with these rights.

- Users may download and print one copy of any publication from the public portal for the purpose of private study or research.

- You may not further distribute the material or use it for any profit-making activity or commercial gain

- You may freely distribute the URL identifying the publication in the public portal 


\section{Accepted Manuscript}

Title: Interference-Blind Microfluidic Sensor for Ascorbic Acid Determination by UV/vis Spectroscopy

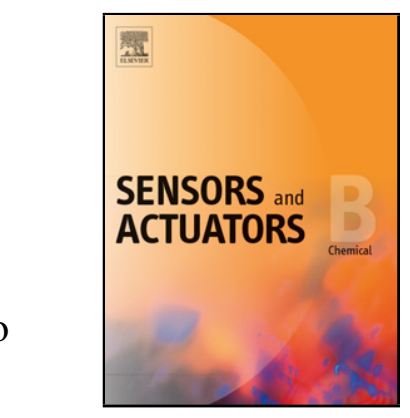

Author: Hongyan Bi Ana Carolina Fernandes Susana Cardoso Paulo Freitas

PII: S0925-4005(15)30538-4

DOI: http://dx.doi.org/doi:10.1016/j.snb.2015.10.072

Reference: SNB 19216

To appear in: Sensors and Actuators B

Received date: 7-8-2015

Revised date: 8-10-2015

Accepted date: 20-10-2015

Please cite this article as: H. Bi, A.C. Fernandes, S. Cardoso, P. Freitas, Interference-Blind Microfluidic Sensor for Ascorbic Acid Determination by UV/vis Spectroscopy, Sensors and Actuators B: Chemical (2015), http://dx.doi.org/10.1016/j.snb.2015.10.072

This is a PDF file of an unedited manuscript that has been accepted for publication. As a service to our customers we are providing this early version of the manuscript. The manuscript will undergo copyediting, typesetting, and review of the resulting proof before it is published in its final form. Please note that during the production process errors may be discovered which could affect the content, and all legal disclaimers that apply to the journal pertain. 


\title{
Interference-Blind Microfluidic Sensor for Ascorbic Acid Determination by UV/vis Spectroscopy
}

\author{
Hongyan $\mathrm{Bi}^{1, *}$, Ana Carolina Fernandes ${ }^{2,3}{\text { Susana } \text { Cardoso }^{2} \text {, Paulo Freitas }}^{1}$ \\ ${ }^{1}$ International Iberian Nanotechnology Laboratory (INL), Av. Mestre José Veiga, 4715-330 Braga, Portugal \\ ${ }^{2}$ INESC Microsistemas e Nanotecnologias (INESC MN), Rua Alves Redol, 9-1, 1000-029 Lisbon, Portugal \\ * Correspondence should be addressed to Dr. Hongyan Bi \\ Tel: + 351253140 112; Fax: +351253140119 \\ E-mail: hongyan.bi@inl.int \\ ${ }^{3}$ Present address: CAPEC-PROCESS, Technical University of Denmark, $2800 \mathrm{Kgs}$, Lyngby, Demark
}

\begin{abstract}
A microfluidic sensor is developed and targeted at specific ingredients determination in drug/food/beverage matrices. The surface of a serpentine polydimethylsiloxane (PDMS) microchannel is modified by enzyme via physisorption. When solutions containing target ingredients pass through the microfluidic channel, enzyme-catalyzed reaction occurs and only converts the target molecules to its products. The whole process is monitored by an end-channel UV/vis spectroscopic detection. Ascorbate oxidase and L-ascorbic acid (AA) are taken as enzyme-substrate model in this study to investigate the feasibility of using the developed strategy for direct quantification of AA in standard solutions and complex matrices. A dietary supplement product, vitamin $\mathrm{C}$ tablet, is chosen as a model matrix to test the microfluidic bio-sensor in real-sample analysis. The results illustrate that the established microfluidic biosensor exhibits good reproducibility, stability, and anti-interference property. Technically, it is easy to realize, depends on low investment in chip fabrication, and simple instrumental procedure, where only $\mathrm{UV} / \mathrm{vis}$ spectrophotometer is required. To sum up, the developed strategy is economical, specific, and accurate, and can be potentially used for fast quantification of ingredient in samples with complex matrix background. It is promising to be widely spread in food industry and quality control department.
\end{abstract}

Keywords: microfluidic sensor; enzyme immobilization; vitamin C; food analysis; UV/vis spectroscopy; ascorbic acid 


\section{Abbreviations}

AA, L-ascorbic acid; UV/vis, UV/visible; PDMS, polydimethylsiloxane; HEPEs, 4-(2-hydroxyethyl)-1piprazineethane-sulfonic acid; RSD, relative standard deviation; OR, oxidation ratio; $\boldsymbol{r}$, linear correlation coefficient; $\boldsymbol{n}$, number of repeated measurements; $\boldsymbol{D}$, difference between two measurements.

\section{Introduction}

Food chemistry is an important topic, and quickly developed during the last years. To date, most analytical chemistry techniques have already been used in food analysis, including mass spectrometry, chromatography, spectroscopy, and electrochemistry. However, conventional food analysis usually needs time-consuming and labour-intensive pretreatment procedures, which counteracts the fast developing food industry and increasing food risk in national and international markets. Therefore, sensing devices for rapid ingredient analysis are highly required. Microfluidic devices have been developed as portable and disposable sensors for numerous assays, showing great promises in chemical analysis. Microfluidics in food analysis and processing has been defined as food microfluidics for food safety and qulity control.[1] A recently published review has summarized the past work and challenges of applying microfluidics in food analysis, and mentioned that the complexity of food samples could limit the microfluidic technology applying in food analysis.[1]

L-ascorbic acid (vitamin $\mathrm{C}$, shortened as AA in the following paragraphs) is an essential antioxidant for human beings with many physiological and biochemical functions.[2] Besides its well-known treatment to scurvy, high-dose of AA has also been used to treat cancer since 1970s, and is still holding the potential as a therapeutic method.[3] In addition, abnormal AA concentration in human body fluids is associated with various diseases.[4] In nature, a wide variety of food sources contain AA, e. g. citrus fruits, pineapples, sweet peppers, broccoli, curly kale, cauliflower, black currants, and dog rose.[5] In food industry, AA is widely used as an antioxidant to avert the formation of carcinogenic nitrosamines in meat and sausage products.[6]

The conventional detection methods for AA include titrimetric analysis, liquid chromatography[7, 8], fluorometric assay[9], spectrophotometric determination,[10] and electrochemical techniques[11]. Titrimetric methods to AA analysis are simple, but usually need big volume of analyte solution. In addition, the endpoint of reaction is usually judged by 
distinguishing color change, which can introduce detection error. Titrimetric analysis method also relies on the reaction between AA and titrant, e.g. the reduction of iodine by AA. The presence of other reductant can influence the analysis result. UV/vis spectrophotometry is alternatively a simple technique and can provide quick analysis. AA has a characteristic and maximum UV/vis absorbance at $266 \mathrm{~nm}$ in $\mathrm{pH} 5.6$ buffer solution. Therefore, it can be easily quantified by UV/vis spectrophotometer in standard solution. However, UV/vis spectrophotometry cannot discriminate the substances that have close absorbance. Proteins, peptides, alcohol, caffeine, and color additives in food sources can also have absorbance near $266 \mathrm{~nm}$ that definitely interfere the determination of AA by UV/vis spectroscopy. Therefore, in complex matrices, such as fruit juice, separation of substrate samples is usually necessary, e. g. by ion-pair liquid chromatography[8], reverse phase high performance liquid chromatography[7], and capillary electrophoresis[12]. However, in the liquid chromatography based methods, the pretreatment of sample, the optimization of chromatographic conditions, and the choice of proper columns must be carefully considered.[4, 7, 8] In the conventional capillary electrophoresis-based analysis, automated sampling may be timeconsuming and conflict with the instability of AA.[10] Escarpa et al. have proposed microchip electrophoresis coupled with electrochemical detection for the separation and quantification of water-soluble vitamin.[13] To date, microchip electrophoresis for the real food sample analysis is still in its infancy, and usually involves the utilization of high voltage for the separation of samples.[14] Another option for working under complex sample matrices is to develop enzymebased methods to selectively sense AA.[15] Indeed, enzyme-coupled electrochemical methods have already been developed to analyze AA and other additives or ingredients in food, which are good in the view of selectivity and specificity, but usually require many technical procedures, such as the pretreatment and modification of electrodes.[16-19]

Although a vast number of studies have been reported to determine ascorbic acid because of its importance in food and human health, to the best knowledge of the authors, there is no available report for AA determination based on microfluidic sensor coupled with UV/vis spectroscopy. In this work, an enzymatic microfluidic sensor coupled with UV/vis spectroscopy for AA quantification is developed, where the pretreatment for eliminating interference from other ingredients can be skipped or greatly simplified. Microfluidic device also holds the great advantages of using tiny volume of reagent, being portable, and easy to automate. During the experiments, ascorbate oxidase was immobilized on the surface of a serpentine 
polydimethylsiloxane (PDMS) microfluidic channel by the virtue of PDMS's adsorption to biomolecules. Ascorbate oxidase is an important oxidase enzyme that can specifically catalyze the oxidation of AA by oxygen to form dehydroascorbic acid. Different from AA with a maximum UV/vis absorbance at $266 \mathrm{~nm}$, the oxidized product of AA, dehydroascorbic acid, has no absorbance at the same wavelength (Fig. B. 1, Appendices). When sampling AA-containing solution through the ascorbate oxidase-loaded microfluidic channel, AA oxidation occurred, leading to an absorbance change at $266 \mathrm{~nm}$ linearly dependent on the initial concentration of AA. With an external standard calibration, quantification of AA from various samples can be realized. Because of the specificity of ascorbate oxidase, influence from interference can be avoided. We have demonstrated this concept by using caffeine as an artificial interference. With the microchip sensor, the content of AA in a vitamin $\mathrm{C}$ tablet was obtained, which was used as an example to test the sensor in real-sample analysis. The stability of the sensor was also considered. In contrast to its inherent instability, ascorbate oxidase in the microfluidic sensor showed relatively good stability during storage, where one external calibration can be functional for days. More aspects like detection limit and tolerance to interference of the developed sensor were also considered.

\section{Materials and methods}

\subsection{Chemicals and solutions}

L-ascorbic acid (reagent grade), ascorbate oxidase (from Cucurbita sp.), hydrochloric acid (HCl, $37 \%)$, hydrogen peroxide $\left(\mathrm{H}_{2} \mathrm{O}_{2}, 30\right.$ wt.\%), sodium hydroxide $(\mathrm{NaOH}, \geq 98 \%)$, glacial acetic acid (HAc, $\geq 99.7 \%$ ), and 4-(2-hydroxyethyl)-1-piprazineethane-sulfonic acid (HEPEs, $\geq 99.5 \%$ ) were purchased from Sigma-Aldrich (MO, USA). Cecrisina ${ }^{\circledR}$ vitamin C effervescent tablets (Johnson \& Johnson, Queluz de Baixo, Portugal, $1 \mathrm{~g}$ of vitamin C per tablet) were bought from a local pharmacy. These chemicals or reagents were used as received without any further purification. Deionized water (DI water, $18.2 \mathrm{M} \Omega \mathrm{cm}$ ) from a Milli-Q system (Millipore, Bedford, MA, USA) was used to prepare all the solutions unless otherwise specified. AA solution was prepared in an acetate buffer $(50 \mathrm{mM}, \mathrm{pH} 5.6)$ prior to each detection. The acetate buffer was prepared by dissolving $1.8 \mathrm{~g} \mathrm{NaOH}$ and $3 \mathrm{~g} \mathrm{HAc}$ in $1 \mathrm{~L}$ DI water. Ascorbate oxidase was dissolved in $10 \mathrm{mM}$ HEPEs buffer ( $\mathrm{pH} 7.5$, adjusted by $0.1 \mathrm{M} \mathrm{NaOH}$ solution), and stored at $-80{ }^{\circ} \mathrm{C}$. All the 
experiments were performed at room temperature and under atmospheric pressure unless otherwise stated.

\subsection{Fabrication of microfluidic chips}

Mask design was done by LASI 7 with the pattern shown in Fig. A. 1 a). The pattern was transferred by Direct Write Laser lithography to a $300 \mathrm{~nm}$-thick aluminum film deposited on a glass hard mask followed by aluminum chemical/wet etching. PDMS microfluidic chips were fabricated by the standard soft lithography method,[20] where a silicon wafer with patterned photoresist (100 $\mu$ m-thick SU-8 50, Sigma-Aldrich, MO, USA) was used as a mold master based on the mask. Precursors (Dow Corning, MI, USA) of PDMS were poured into the mold master and cured at $75{ }^{\circ} \mathrm{C}$ for 1 hour. The cured PDMS was manually peeled off, and pretreated by oxygen plasma (UVO Cleaner, Model 144AX-22, Jelight Company, Inc. Irvine, CA, USA) together with a glass substrate. Irreversible bonding between PDMS and glass was accomplished by joining the treated surfaces. A fabricated microfluidic chip is shown in Fig. A. 1 b), Appendices. The serpentine channel is $100 \mu \mathrm{m}$ in depth and $100 \mu \mathrm{m}$ in width. The total actual volume was measured by infusing water into the channel with a syringe pump (Harvard apparatus, PHD ultra series, Instech Laboratories, Inc., PA, USA) and a glass syringe (500 $\mu \mathrm{L}$, Hamilton, NV, USA), and calculated from syringe-pump-panel recorded data.

\subsection{UV/vis spectrophotometric measurement}

UV/vis absorbance measurement was carried out using a USB4000 Ocean Optics UV/vis spectrophotometer. During the UV/vis measurement of microfluidic output solution, the abovementioned syringe pump was used to inject substrate solution into the microfluidic channel with disposable plastic syringes ( $1 \mathrm{~mL}$, HSW Air-tite Norm-Ject, Tuttlingen, Germany). A UV/vis flow-cell (FIA-Z-SMA-ML-PL, FIAlab, WA, USA) was connected to the outlet of the microfluidic channel by tubing and couplers to supervise the UV/vis absorbance of microfluidic output solution in real time. The picture of the UV/vis flow-cell is shown as Fig. C. 1 c), Appendices. Luer stubs (blunt needles), tubing, and couplers were obtained from Instech (Winsum, The Netherlands). The tubing and flow-cell were thoroughly washed by water and buffer between different measurements. A detection order of low concentration to high concentration of substrate was chosen to diminish error. 


\subsection{Immobilization of enzyme in microfluidic channel}

Immobilization condition of enzyme to the microfluidic channel is referred to previously published studies.[21-23] $1 \mu \mathrm{g} / \mathrm{mL}$ ascorbate oxidase solution in $10 \mathrm{mM}$ HEPEs buffer (pH 7.5) was continuously sampled through the serpentine microfluidic channel at $20 \mu \mathrm{L} / \mathrm{min}$ for $1 \mathrm{~h}$. Then the microfluidic channel was flushed by $10 \mathrm{mM}$ HEPEs buffer (pH 7.5) at $20 \mu \mathrm{L} / \mathrm{min}$ for $20 \mathrm{~min}$ to remove the excess and loosely bound enzymes. The output solution during microchannel flushing was collected as waste to avoid contamination of after-channel tubings.

\subsection{AA oxidation catalyzed by ascorbate oxidase in microchip}

For AA oxidation in the microfluidic device, AA in $50 \mathrm{mM}$ acetate buffer ( $\mathrm{pH} 5.6)$ was injected into the microfluidic channel loaded with ascorbate oxidase. By controlling the substrate solution to flow through the channel at different flow rates, the reaction time for AA oxidation under enzyme catalysis was adjusted. The characteristic absorbance of AA at $266 \mathrm{~nm}$ was continuously recorded by the above mentioned UV/vis spectrophotometer to monitor the decrease of AA concentration during oxidation. The absorbance data were collected by OceanView software to display the averaged absorbance between 265 and $267 \mathrm{~nm}$ versus record time.

\subsection{Stability of immobilized enzyme in microfluidic channel}

The catalysis ability of immobilized ascorbate oxidase in a microchannel was characterized by the oxidation ratio $(\mathrm{OR})$ of $\mathrm{AA}$ after certain reaction time. The reaction was performed by injecting $100 \mu \mathrm{M}$ AA solution through the microchannel under a flow rate of $5 \mu \mathrm{L} / \mathrm{min}$. The OR was determined by dividing the concentration of microchip output AA solution by the initial AA concentration $(100 \mu \mathrm{M})$. To evaluate the binding stability of immobilized enzyme, microchannels immobilized with enzyme were flushed continuously by $50 \mathrm{mM}$ acetate buffer. The catalysis ability of remained ascorbate oxidase was characterized after various flushing hours. To study the stability of immobilized enzyme during chip storage, enzyme-loaded microchannels were stored at $4{ }^{\circ} \mathrm{C}$ until use. The catalysis ability of the immobilized ascorbate oxidase was regularly evaluated during 2 weeks.

\subsection{Measurement of AA content in vitamin $C$ tablet}


To determine AA content in a vitamin $\mathrm{C}$ tablet by the enzyme-loaded microfluidic sensor, one vitamin $\mathrm{C}$ tablet was precisely weighed and freshly prepared as aqueous solution with a concentration of $10 \mathrm{~g} / \mathrm{L}$, and then diluted to a proper concentration by acetate buffer $(50 \mathrm{mM}, \mathrm{pH}$ 5.6). To obtain the external calibration curve, a series of standard AA solutions in $50 \mathrm{mM}$ acetate buffer were directly injected into the UV/vis flow-cell to determine their original absorbance at $266 \mathrm{~nm}$, and then into an enzyme-loaded microfluidic sensor to determine their UV absorbance at $266 \mathrm{~nm}$ after on-chip oxidation. The differences of absorbance at $266 \mathrm{~nm}$ before and after oxidation were calculated and plotted as a function of the original AA concentrations. All the tubings were thoroughly washed between different measurements by water and buffer solution, or changed when contaminated by enzyme solution. All the measurements were duplicated at least three times to guarantee reproducibility.

\section{Results and discussion}

\subsection{Microfluidic device for food ingredient analysis}

Scheme 1 depicts the PDMS microfluidic device integrated with real time UV/vis spectroscopy for food ingredient analysis. Standard solution with target substrate is injected into the microfluidic channel, which is preloaded with enzymes by physisorption. The enzyme-catalyzed substrate reaction occurs inside the microchip. In order to monitor the characteristic absorbance change of target substrate before and after on-chip oxidation as a function of the original substrate concentration, the output solution from the microfluidic channel is directed to a UV/vis flow-cell detection system. The characteristic UV/vis absorbance of output solution increases and reaches a plateau when the UV/vis flow-cell detection channel is completely filled by the output solution. The stabilized plateau signal corresponds to the absorbance of output solution. As shown in Appendix $\mathrm{C}$, the volume between the end of microfluidic channel and the flow-cell detector is determined by the inner diameter and length of the connection tubings, and affects the response time for signal rising from background level to the plateau, but not the intensity of the plateau.

\subsection{On-chip ascorbic acid oxidation}


To detect AA, ascorbate oxidase was immobilized in the microfluidic channel. The $\mathrm{pH}$ optimum for the enzymatic activity of ascorbate oxidase from Cucurbita sp. is in the range of pH 5.5 to 7.0. In the present study, an acetate buffer with $\mathrm{pH} 5.6(50 \mathrm{mM})$ was chosen to prepare all the AA solutions. In this buffer, AA has characteristic and maximum UV/vis absorbance at $266 \mathrm{~nm}$ with molar attenuation coefficient as $(1.248 \pm 0.005) \times 10^{4} \mathrm{~L} \mathrm{~mol}^{-1} \mathrm{~cm}^{-1}$ in the range of $12.5 \mu \mathrm{M}$ to 100 $\mu \mathrm{M}\left(r^{2}=0.9908\right)$, as shown in Appendix B.

The amount of enzyme immobilized on the surface of the PDMS microfluidic channel was controlled to be saturated to maximize its catalysis effect to AA oxidation. A stronger catalysis effect can lead to more significant absorbance change of AA at $266 \mathrm{~nm}$ before and after passing through the microfluidic sensor, thereby a more sensitive detection. Based on the results of a previous publication on the adsorption of proteins to PDMS thin film, $1 \mathrm{~h}$ of adsorption was performed for the ascorbate oxidase immobilization. A relatively high concentration of enzyme (i.e., $1 \mu \mathrm{g} / \mathrm{mL}$ ) was chosen for immobilization to maintain their native conformation (maximum enzymatic activity).[21-23]

The freshly prepared enzyme-loaded microchip was used for AA oxidation. Fig. 1 a) shows a representative change of the supervised UV/vis absorbance at $266 \mathrm{~nm}$ of $100 \mu \mathrm{M}$ AA after flowing through the microchip at different flow rates. The reaction time between the substrate and enzyme inside the microchannel is determined by the total volume of the microchannel and sample flow rate. In this study, the measured total volume of the serpentine microchannel is $3.42 \pm 0.25 \mu \mathrm{L}$ $(n=4)$. A lower flow rate can lead to a longer reaction time, and then a larger enzymatic transformation of AA, which is shown as a lower plateau UV/vis absorbance signal on Fig. 1 a). The larger enzymatic transformation is good for sensitive AA quantification. However, a low flow rate also results in a long response time, making the analysis time consuming.

Fig. $1 \mathrm{~b}$ ) plots the UV/vis absorbance at $266 \mathrm{~nm}$ and concentration of AA from different output solutions versus the reaction time under the catalysis of the immobilized ascorbate oxidase in the microchip. The inset of Fig. 1 b) shows that the enzyme catalyzed reaction follows a pseudo-first order reaction kinetics with a simulated reaction rate constant of $(7.361 \pm 0.633) \times 10^{-3} \mathrm{~s}^{-1}\left(r^{2}=\right.$ 0.9713), illustrating that the enzyme's Michaelis constant $\left(K_{\mathrm{M}}\right)$ is much larger than the initial concentration of AA $(100 \mu \mathrm{M})$, in accordance with previous publication.[24] The immobilized enzyme has a high local concentration, leading to fast enzyme-catalyzed AA oxidation. The 
confined space of the microfluidic channel also contributes to the high efficiency of the reaction.[25] The serpentine microfluidic channel is very long with many running-track like structures that favors the fluctuation of substrate solution in the microfluidic channel (Fig. A. $1 \mathrm{c}$, Appendices)). Thus, the mass transfer process of substrate inside the microfluidic channel can be accelerated to fully contact with the immobilized enzyme for efficient reaction.[26] Combining all the advantages, the enzyme-loaded serpentine microfluidic sensor can provide a very sensitive detection to its substrate.

\subsection{Reproducibility of enzyme immobilization}

To be used as a sensor for AA quantification, the reproducibility of enzyme immobilization, thus the reproducible sensor performance, must be considered. Freshly prepared AA solution was injected into three independently prepared microfluidic channels that were modified with $1 \mu \mathrm{g} / \mathrm{mL}$ enzymes for 1 hour at injection flow rates of 20,10 , and $5 \mu \mathrm{L} / \mathrm{min}$, respectively. Table 1 compares the UV/vis absorbance of $100 \mu \mathrm{M}$ AA after flowing through the three microchannels at $5 \mu \mathrm{L} / \mathrm{min}$. The results show that the 3 different microchannels have similar catalysis effects (RSD: $7.7 \%$ ), demonstrating that the enzyme immobilization by physisorption is well reproducible, and that the injection flow rate from 5 to $20 \mu \mathrm{L} / \mathrm{min}$ for enzyme immobilization does not influence the performance of the microchip sensor. Therefore, low injection flow rate for enzyme immobilization can be chosen to save enzyme.

\subsection{Stability of immobilized enzyme}

As an enzyme based microfluidic sensor, it is important that the enzyme activity is stable during substrate analysis periods. A stable activity during days is preferred, so that frequent calibration of the sensor can be avoided. The bioactivity decay of immobilized enzyme with time is usually observed, and is determined by immobilization methods, operation condition, and enzyme itself.[27] In this study, the stability of immobilized ascorbate oxidase is evaluated from two aspects: $i$ ) under continuous flushing by buffer solution and $i i)$ under various storage time. The activity of enzyme in a microfluidic sensor is evaluated by the oxidation ratio (OR) of AA, the concentration of microchip output AA / the initial AA concentration $(100 \mu \mathrm{M})$, when it is sampled through the microfluidic sensor at $5 \mu \mathrm{L} / \mathrm{min}$. Different OR of the same sample solution with the same reaction time is due to the change in reaction rate constant, which is in-turn related to the 
concentration of active enzyme. Herein, we assume freshly prepared microfluidic sensors with normalized activity as 1.0. The normalized activity of sensor is calculated as $(\mathrm{OR})_{\mathrm{i}} /(\mathrm{OR})_{0}$, where $(\mathrm{OR})_{\mathrm{i}}$ is the OR obtained with microfluidic sensor after storage or continuous flushing, while $(\mathrm{OR})_{0}$ is the OR obtained with the freshly prepared microfluidic sensor.

To evaluate the immobilization stability of the enzyme by physisorption under continuous flushing, a freshly prepared enzyme-loaded microfluidic chip was continuously flushed by $50 \mathrm{mM}$ acetate buffer (pH 5.6) at $20 \mu \mathrm{L} / \mathrm{min}$. Under such a strong shearing force, as shown in Fig. 2 a), the physisorptively loaded enzyme in the microfluidic channel could provide stable catalysis in 2 hours. However, after 3 hours, the catalysis ability of the enzyme declined suddenly. The decline can be attributed to two reasons: $i$ ) complete elution of immobilized enzyme from the channel, and ii) enzyme activity loss during the experiment. Indeed, we observed that ascorbate oxidase is very unstable that can lose completely its activity after 5 hours of storage in bulk solution $(2 \mu \mathrm{g} / \mathrm{mL}$, in pH 5.6 acetate buffer) under room temperature. Therefore, the sudden decline may be the result of enzyme activity loss. Actually, the physisorption method was chosen for the immobilization of ascorbate oxidase also because of the unstable property of the enzyme. The direct physisorption of ascorbate oxidase to the surface of microfluidic channel is procedurally facile, and could make the immobilization accomplished in relatively short time to maintain the maximum bio-activity of the enzyme.

Although the enzyme-loaded microfluidic sensor can be deactivated in hours under continuous and intensive flushing at room temperature, it can be stored for days under $4{ }^{\circ} \mathrm{C}$. Freshly prepared $100 \mu \mathrm{M}$ AA solution was injected into the microfluidic sensor to check the activity of the immobilized enzyme. Each investigation took only $<10$ min. Fig. 2 b) compares the catalysis ability of immobilized ascorbate oxidase versus the storage time. The freshly immobilized ascorbate oxidase has the highest activity. After 1 day of storage, half of the initial activity is kept. However, from day 3 to day 7, the supervised activity of the microfluidic sensor is stable and remains around half of the freshly prepared one. After 12 days of storage, the activity of the microfluidic sensor drops to only $6.1 \%$ that of the freshly prepared one. Therefore, it is the best to use the microfluidic sensor after 1 day of storage but before 7 days of storage, where the microfluidic sensor performance is stable and needs only one calibration during the 5 days. Actually, the storage time is mainly limited by the instability of ascorbate oxidase itself. Even 
under $-80{ }^{\circ} \mathrm{C}$, water dissolved ascorbate oxidase lost $\sim 75 \%$ of its bioactivity after 13 days of storage. When the activity of the microfluidic sensor is completely lost, it can be easily regenerated in 1 hour with the same serpentine microchip by enzyme physisorption, so that the microchip itself do not have to be disposable.

\subsection{Specificity of the microfluidic sensor}

The main advantage of the enzymatic microfluidic sensor is that it can keep blind to interference during analysis without sample pretreatment, e.g. separation. To verify the specificity of the developed microfluidic sensor, caffeine was added to the solution of AA as an artificial interference. As mentioned earlier, due to the close absorbance wavelength of AA and caffeine in the $U V / v i s$ range, caffeine can interfere the measurement of AA by UV/vis absorbance spectroscopy. Fig. D. 1, Appendices, shows the UV/vis absorbance spectra of AA solution, caffeine solution, their algebraic addition, and the mixture of AA and caffeine. The summed absorbance ( $A_{\text {detected }}$ ) can be expressed, according to the Beer-Lambert law, as:

$$
A_{\text {detected }}=\varepsilon_{A A, 266 n m} b c_{A A}+\varepsilon_{\text {Caffeine } 266 n m} b c_{\text {Caffine }}
$$

Where $A_{\text {detected }}$ is the detected absorbance at $266 \mathrm{~nm}$ of the solution with AA and caffeine, $\varepsilon_{A A, 266 n m}$ and $\varepsilon_{\text {Caffeine,266nm }}$ are the molar attenuation coefficients of AA and caffeine at $266 \mathrm{~nm}$, respectively, $b$ is the light path length $(1 \mathrm{~cm}), c_{A A}$ and $c_{\text {Caffine }}$ are the molar concentration of AA and caffeine in the solution, respectively. Obviously, the UV/vis spectroscopy cannot specifically analyze an unknown sample containing AA when there is also caffeine or other substances with absorbance near $266 \mathrm{~nm}$.

With the enzyme-loaded microfluidic sensor, specific response to AA can be obtained. As shown in Fig. 3 b), when the sample injected into the microfluidic sensor was a solution including AA and caffeine (37.5 $\mu \mathrm{M}$ each), a dramatic decline of the absorbance, $-\Delta A=A 0-A^{\prime}=0.323$, at $266 \mathrm{~nm}$ was observed. However, when a solution containing only caffeine was injected through the same microfluidic sensor, there was no sensible absorbance change at $266 \mathrm{~nm}$ (Fig. 3 a), and can be ascribed to detection error. When the caffeine was in large excessive (10 $\mu \mathrm{M}$ AA and $100 \mu \mathrm{M}$ 
caffeine, Fig 3 c), a signal drop $(-\Delta A)$ of 0.053 was calculated, demonstrating the presence of AA in the sample. The results show that the ascorbate oxidase-loaded microfluidic sensor is specific to the analysis of AA, demonstrating the potential of using this strategy to selectively assay AA under complex matrices.

\subsection{Calibration of the enzyme-loaded microfluidic sensor, and its application in vitamin C tablet analysis}

The protein or other ingredients in the dietary supplement products may interfere the quantification of AA directly by UV/vis spectroscopy. A dietary supplement product, vitamin C tablet was chosen as a representative model to test the quantitative analysis ability of the sensor for real samples. Considering that the microchip sensor between the $3^{\text {rd }}$ and $7^{\text {th }}$ days of storage can give stable performance, the newly built ascorbate oxidase microchip was stored for 2 days at $4{ }^{\circ} \mathrm{C}$ to stabilize its performance.

During the experiments, an external calibration of the microfluidic sensor was firstly performed with standard AA solutions at different concentrations. The AA solution was sampled through the microfluidic sensor at $5 \mu \mathrm{L} / \mathrm{min}$. Absorbance change of AA at $266 \mathrm{~nm}$ before and after on-chip oxidation, $-\Delta A$, was plotted as a function of the original concentration of $\mathrm{AA}\left(c_{0}\right)$ to obtain calibration curve. Good linearity $(r=0.9827)$ was observed in the used $c_{0}$ range as shown in Fig. 4, with the calibration curve $y=a x+b, a=0.001639 \pm 0.000154, b=-0.001890 \pm 0.008660$. The enzymatic transformation of AA, responsed by $(-\Delta A)$, is not high in the case here, mainly because the microchip was not used at its highest activity. The sensitivity can be improved by prolonging the contacting time of substrate to enzymes (using low sample infusion rate), though the measurement accordingly will need more time.

The vitamin $\mathrm{C}$ tablet was freshly prepared as aqueous solution with concentration of $10 \mathrm{~g} / \mathrm{L}$, then diluted 400 time, 800 times, and 1600 times respectively with $50 \mathrm{mM}$ acetate buffer $(\mathrm{pH} 5.6)$. The diluted solution was sampled through the microfluidic sensor at $5 \mu \mathrm{L} / \mathrm{min}$ separately. With the obtained $\Delta A$ and the calibration curve, AA concentrations in the diluted samples could be calculated. The obtained averaged AA content $(\mathrm{w} / \mathrm{w})$ in the vitamin $\mathrm{C}$ tablet was $(21.8 \pm 1.5) \%(n=$ 3). The provider indicates that each vitamin $\mathrm{C}$ tablet contains $1 \mathrm{~g}$ AA. The weight of one vitamin $\mathrm{C}$ tablet is $4.504 \pm 0.033 \mathrm{~g}(n=4)$. Thus the theoretical AA content in the used vitamin C tablets could 
be calculated as $(22.2 \pm 0.2) \%$. The difference $(D)$ between $21.8 \pm 1.5$ and $22.2 \pm 0.2$ is $0.4 \pm 1.7$, where zero is comfortably within the uncertainty range of $D$, indicating that the measurement by our sensor strategy agrees well with the provider's datum.[28] The results show that it's practically feasible to analyze AA content in unknown samples with complex matrix by the enzymatic microfluidic sensor.

\subsection{Limit of detection, limit of quantification, and tolerance to interference of the microfluidic sensor}

Limit of detection (LOD) and limit of quantification (LOQ) are always interesting for analysts.[29] Usually, ascorbic acid concentration in food sample is quite high, and it's necessary to dilute sample to the detectable concentration range (less than $100 \mu \mathrm{M}$ ). However, when the ratio of interference to AA is very high, over dilution can make AA out of the LOD/LOQ of the developed microchip method.

LOD is normally defined as 3 times of standard deviation of blank, and LOQ as 10 times. Under well controlled experimental condition, the UV/vis flow cell system gives a SD $(\delta)$ of 0.0005 for blank. Therefore, when the absorbance change $(\Delta A)$ before and after passing a sample through the microchip reaches 0.0015 , AA in the sample is supposed to be detectable; while when $\Delta A$ reaches 0.0050 , the amount of $\mathrm{AA}$ is supposed to be quantifiable. For different microchips or the same microchip after different storage time, the sensitivity of the microchip sensor to AA might vary. According to the performance of the microchip shown in Fig. 4, with the calibration curve $(y=0.00164 x-0.00189$ ), a LOD $\approx 1 \mu \mathrm{M}$ (for $-\Delta A=0.0015$ ), and a $\mathrm{LOQ} \approx 4 \mu \mathrm{M}$ (for $-\Delta A=$ $0.0050)$ can be expected. In general, with the current design of microchip, few $\mu \mathrm{M}$ is a reasonable value for LOQ. If lower $\mathrm{LOD} / \mathrm{LOQ}$ is required, the enzymatic transformation ratio may be increased by using a microchannel with larger specific surface area for enzyme immobilization, or by decreasing the sample infusion rate for longer reaction time.

The tolerance to interference of the microchip for AA analysis is further considered. When there is interference in a sample, the detected absorbance is,

$$
A_{\text {detected }}=\varepsilon_{\text {target }, \lambda} b c_{\text {target }}+\varepsilon_{\text {interference }, \lambda} b c_{\text {interference }}
$$


where the light path length, $b$, is $1 \mathrm{~cm} ;{ }^{\varepsilon_{\text {target }, \lambda}}$ is the molar attenuation coefficient of target analyte at its characteristic wavelength, $\lambda$; and $\varepsilon_{\text {interference, } \lambda}$ is the molar attenuation coefficient of interference at $\lambda$. The maximum value of $A_{\text {detected }}$ is usually around 1 . Therefore, the lowest detectable $c_{\text {target }}$ is restricted by $c_{\text {interference, }} \varepsilon_{\text {target }, \lambda}$ and $\varepsilon_{\text {interference }, \lambda}$.

By taking caffeine and AA as models of interference and target analyte, the molar attenuation coefficient of AA in the used buffer solution is $(1.248 \pm 0.005) \times 10^{4} \mathrm{~L} \mathrm{~mol}^{-1} \mathrm{~cm}^{-1}$ at $266 \mathrm{~nm}$, and the molar attenuation coefficient of caffeine in water is $1.0 \times 10^{4} \mathrm{~L} \mathrm{~mol}^{-1} \mathrm{~cm}^{-1}$ at $273 \mathrm{~nm}$. Therefore, the two compounds have close molar attenuation coefficient at $266 \mathrm{~nm}$, and the maximum summed concentration of caffeine and AA that can be detected by UV/vis spectrophotometer should be around $100 \mu \mathrm{M}\left(A_{\text {detected }} \approx 1\right)$. Assuming that the LOQ of AA by the developed microchip is $x \mu \mathrm{M}$, the maximum allowable concentration of caffeine is then $(100-x) \mu \mathrm{M}$. Therefore, the maximum ratio between caffeine and $\mathrm{AA}$ can be $(100-x) / x$ in the original sample. Specifically, as discussed earlier the LOQ should be several $\mu \mathrm{M}$, then the maximum ratio can be around 10 . Indeed, it has been demonstrated in Fig. 3 that AA can be detected when $10 \mu \mathrm{M}$ AA in the presence of 100 $\mu \mathrm{M}$ caffeine, in accordance with this prediction. However, if the molar ratio of caffeine to AA is too high, e.g. $>100$, or if the molar attenuation coefficient of interference is very large, pretreatment to the sample may be necessary. As an example, when the interference is induced by excess proteins, which can usually have several or dozen times the molar attenuation coefficient at $280 \mathrm{~nm}$ of AA, the direct analysis of AA by the enzyme-loaded microchip sensor is difficult, and then pre-elimination of the proteins by molecular weight cut-off filters is necessary.

\section{Conclusion}

By taking L-ascorbic acid and ascorbate oxidase as models, a serpentine microfluidic channel coupled with UV/vis spectroscopy was developed as a biosensor and applied to study the content of AA in dietary supplement products. The results show that physisorptively immobilized enzymes on the PDMS surface are effective for catalysis, and relatively stable under continuous and intense flushing or storage at $4{ }^{\circ} \mathrm{C}$. Considering that each measurement takes only minutes, it's applicable to use the microfluidic sensor for drug/food/beverage analysis. We also found that the microfluidic chip itself doesn't have to be disposable, and enzyme can be reloaded to reactivate the sensor for 
the purpose of economy. The utilization of the enzyme-loaded microfluidic sensor is facile, and relies on low investment in fabrication and simple detection procedure. Furthermore, the method exhibits good anti-interference property, reproducibility, and stability. In combination with a miniaturized UV/vis spectrophotometer, the whole detection system can be portable and used for on-site analysis. The principle can be duplicated for the detection of many other food ingredients, as long as the target substrate has a characteristic UV/vis absorbance and can be consumed under the catalysis of a specific enzyme. Therefore, we would expect a wide spread of the technique in food industry and quality control department.

\section{Acknowledgments}

This work is supported by European Commission's 7th RTD Framework programme PEOPLE Marie Curie actions - and NanoTRAINforGrowth COFUND Scheme ( ${ }^{\circ}$ 600375). INESC-MN acknowledges Pest-OE/CTM/LA0024/ 2011 and EXCL/CTM-NAN/0441/2012 projects. 


\section{Reference}

[1] A. Escarpa, Lights and shadows on Food Microfluidics, Lab on a Chip, 14 (2014) 3213-3224.

[2] A. Hacisevki, An overview of ascorbic acid biochemistry, J. Fac. Pharm, Ankara, 38 (2009) 233-255.

[3] J. Du, J.J. Cullen, G.R. Buettner, Ascorbic acid: Chemistry, biology and the treatment of cancer, Biochim. Biophys. Acta-Rev. Cancer, 1826 (2012) 443-457.

[4] R. Zuo, S. Zhou, Y. Zuo, Y. Deng, Determination of creatinine, uric and ascorbic acid in bovine milk and orange juice by hydrophilic interaction HPLC, Food Chemistry, 182 (2015) 242-245.

[5] S. Nojavan, F. Khalilian, F.M. Kiaie, A. Rahimi, A. Arabanian, S. Chalavi, Extraction and quantitative determination of ascorbic acid during different maturity stages of Rosa canina L. fruit, Journal of Food Composition and Analysis, 21 (2008) 300-305.

[6] T.N. Shekhovtsova, S.V. Muginova, J.A. Luchinina, A.Z. Galimova, Enzymatic methods in food analysis: determination of ascorbic acid, Anal. Chim. Acta, 573 (2006) 125-132.

[7] P. Emadi-Konjin, Z. Verjee, A.V. Levin, K. Adeli, Measurement of intracellular vitamin C levels in human lymphocytes by reverse phase high perfon-nance liquid chromatography (HPLC), Clin. Biochem., 38 (2005) 450-456.

[8] Y. Hernandez, M.G. Lobo, M. Gonzalez, Determination of vitamin C in tropical fruits: A comparative evaluation of methods, Food Chemistry, 96 (2006) 654-664.

[9] N.W. Dexter Canoy, Ailsa Welch, Sheila Bingham, Robert Luben, Nicholas Day, and Kay-Tee Khaw, Plasma ascorbic acid concentrations and fat distribution in 19068 British men and women in the European Prospective Investigation into Cancer and Nutrition Norfolk cohort study, Am. J. Clin. Nutr., 82 (2005) 1203 1209.

[10] T. Moeslinger, M. Brunner, I. Volf, P.G. Spieckermann, Spectrophotometric Determination of Ascorbic-Acid and Dehydroascorbic Acid, Clin. Chem., 41 (1995) 1177-1181.

[11] A.M. Pisoschi, A.F. Danet, S. Kalinowski, Ascorbic Acid Determination in Commercial Fruit Juice Samples by Cyclic Voltammetry, Journal of Automated Methods \& Management in Chemistry, (2008).

[12] W.S. Law, P. Kuban, J.H. Zha, S.F.Y. Li, P.C. Hauser, Determination of vitamin C and preservatives in beverages by conventional capillary electrophoresis and microchip electrophoresis with capacitively coupled contactless conductivity detection, Electrophoresis, 26 (2005) 4648-4655.

[13] A.G. Crevillen, M. Pumera, M.C. Gonzalez, A. Escarpa, Carbon nanotube disposable detectors in microchip capillary electrophoresis for water-soluble vitamin determination: Analytical possibilities in pharmaceutical quality control, Electrophoresis, 29 (2008) 2997-3004. 
[14] A. Escarpa, M. Cristina Gonzalez, M.A. Lopez Gil, A.G. Crevillen, M. Hervas, M. Garcia, Microchips for CE: Breakthroughs in real-world food analysis, Electrophoresis, 29 (2008) 4852-4861.

[15] Introduction to Enzymes, http://www.worthington-biochem.com/introbiochem/Enzymes.pdf, (Accessed June 2015).

[16] B.K. Chethana, Y.A. Naik, Electrochemical oxidation and determination of ascorbic acid present in natural fruit juices using a methionine modified carbon paste electrode, Analytical Methods, 4 (2012) 37543759 .

[17] F. Li, H. Wu, M. Cui, Y. Zhang, C. Dong, J. Wang, S. Shuang, M.M.F. Choi, L-Ascorbic acid biosensing assay from enzyme-immobilized pig bladder membrane as a novel platform, Analytical Methods, 5 (2013) 1253-1258.

[18] O.A. Farghaly, R.S.A. Hameed, A.-A.H. Abu-Nawwas, Analytical Application Using Modern Electrochemical Techniques, International Journal of Electrochemical Science, 9 (2014) 3287-3318.

[19] A.M. Pisoschi, Determination of Several Food Additives and Ingredients by Electrochemical Techniques, Biochemistry \& Analytical Biochemistry, 2 (2013) e140.

[20] B. Huang, H.K. Wu, S. Kim, R.N. Zare, Coating of poly(dimethylsiloxane) with n-dodecyl-beta-Dmaltoside to minimize nonspecific protein adsorption, Lab on a Chip, 5 (2005) 1005-1007.

[21] K.E. Sapsford, F.S. Ligler, Real-time analysis of protein adsorption to a variety of thin films, Biosens. Bioelectron., 19 (2004) 1045-1055.

[22] K.Y. Chumbimuni-Torres, R.E. Coronado, A.M. Mfuh, C. Castro-Guerrero, M.F. Silva, G.R. Negrete, R. Bizios, C.D. Garcia, Adsorption of proteins to thin-films of PDMS and its effect on the adhesion of human endothelial cells, RSC Adv., 1 (2011) 706-714.

[23] L. Yu, Z.S. Lu, Y. Gan, Y.S. Liu, C.M. Li, AFM study of adsorption of protein A on a poly(dimethylsiloxane) surface, Nanotechnology, 20 (2009).

[24] R. Girones, M. Antonia Ferrus, J. Luis Alonso, J. Rodriguez-Manzano, B. Calgua, A. de Abreu Correa, A. Hundesa, A. Carratala, S. Bofill-Mas, Molecular detection of pathogens in water - The pros and cons of molecular techniques, Water Research, 44 (2010) 4325-4339.

[25] H. Bi, L. Qiao, J.-M. Busnel, B. Liu, H.H. Girault, Kinetics of Proteolytic Reactions in Nanoporous Materials, Journal of Proteome Research, 8 (2009) 4685-4692.

[26] T. Aoki, Incorporation of Individual Casein Constituents into Casein Aggregates Cross-Linked by Colloidal Calcium-Phosphate in Artificial Casein Micelles, J. Dairy Res., 56 (1989) 613-618.

[27] W. Laiwattanapaisal, J. Yakovleva, M. Bengtsson, T. Laurell, S. Wiyakrutta, V. Meevootisom, O. Chailapakul, J. Emneus, On-chip microfluidic systems for determination of L-glutamate based on enzymatic recycling of substrate, Biomicrofluidics, 3 (2009). 
[28] A Summary of Error Propagation, http://ipl.physics.harvard.edu/wpuploads/2013/03/PS3_Error_Propagation_sp13.pdf, (Accessed June 2015).

[29] J. Vogelgesang, Limit of Detection And Limit Of Determination - Application of Different Statistical Approaches to an Illustrative Example of Residue Analysis, Fresenius Zeitschrift Fur Analytische Chemie, 328 (1987) 213-220. 


\section{Biographies}

Hongyan Bi is a research fellow worked at the International Iberian Nanotechnology Laboratory (INL), with the expertise in analytical chemistry. She received her PhD degree from the Swiss Federal Institute of Technology in Lausanne (EPFL) in 2010. Her current interests include microfluidics and biosensors.

Ana Carolina Fernandes is currently pursuing her doctoral studies at the Technical University of Denmark (Lyngby, Demark). Her research interests are microreactors. She obtained her master degree in the field of biological engineering from the Technical University of Lisbon in 2012, and worked as a research assistant at the INESC-MN (Lisbon, Portugal) until 2014.

Susana Cardoso has been invited as associated professor in the physics department at the Instituto Superior Técnico since 2003, and is meanwhile working as a principle investigator at the INESCMN (Lisbon, PT). She received her PhD degree in physics from the Instituto Superior Técnico (Lisbon, PT) in 2002. Her current interests are bio- and magnetic sensors.

Paulo Freitas is a full professor in the physics department at the Instituto Superior Técnico (Lisbon, PT), and the director of the INESC-MN (Lisbon, PT), and the deputy director general of the International Iberian Nanotechnology Laboratory (INL). He got his $\mathrm{PhD}$ degree from the Carnegie Mellon University (PA, USA) in 1986. His current interests include spintronics, bioelectronics, and biosensors. 


\section{Figure captions}

Scheme 1. Schematic illustration of the microfluidic sensor integrated with after-channel UV/vis spectrophotometric detection for food ingredient analysis. The microchannel is immobilized with enzymes to catalyze the consumption of target molecules.

Fig. 1. a) Representative UV/vis absorbance signal of AA solution after passing through the microfluidic sensor at different flow rates (indicated besides each curve with the unit of $\mu \mathrm{L} / \mathrm{min}$ ). AA solution was freshly prepared with the initial concentration of $100 \mu \mathrm{M}$ in $50 \mathrm{mM} \mathrm{HAc} / \mathrm{NaAc}$ buffer ( $\mathrm{pH}$ 5.6). The absorbance was averaged between the wavelength of 265 and $267 \mathrm{~nm}$. b) UV/vis absorbance and AA concentration change as a function of reaction time. Inset is the semi-logarithm plot of the concentration change (mean) of AA as a function of reaction time (mean). $c_{0}$ is the starting concentration of $\mathrm{AA}(100 \mu \mathrm{M})$, and $c_{\mathrm{t}}$ is the concentration of AA at reaction time, $t$.

Fig. 2. Normalized activity of the enzyme-loaded PDMS microchip sensor to substrate after (a) continuous flushing by $50 \mathrm{mM}$ acetate buffer at $20 \mu \mathrm{L} / \mathrm{min}$, and (b) storage under $4{ }^{\circ} \mathrm{C}$. Error bar shows the standard deviation. The flow rate used to inject AA was $5 \mu \mathrm{L} / \mathrm{min}$. AA solution was freshly prepared in $50 \mathrm{mM}$ acetate buffer (pH 5.6) with the initial concentration of $100 \mu \mathrm{M}$. Ascorbate oxidase was preloaded in the microfluidic channels by flowing $1 \mu \mathrm{g} / \mathrm{mL}$ ascorbate oxidase in $10 \mathrm{mM}$ HEPEs buffer through the channels at $20 \mu \mathrm{L} / \mathrm{min}$ for 1 hour. Dashed line is used to guide the view.

Fig. 3. Collected absorbance change at $266 \mathrm{~nm}$ of solutions containing a) only caffeine $(37.5 \mu \mathrm{M})$, b) AA and caffeine (37.5 $\mu \mathrm{M}$ each), and c) $10 \mu \mathrm{M}$ AA and $100 \mu \mathrm{M}$ caffeine, before (A0) and after (A') passing through the enzyme-loaded microfluidic sensor at $5 \mu \mathrm{L} / \mathrm{min}$. Arrows indicate the time when it is started to sample the solution through the microfluidic channel. The absorbance was averaged between the wavelength of 265 and $267 \mathrm{~nm}$. The used microfluidic channel was freshly prepared by flowing $2 \mu \mathrm{g} / \mathrm{mL}$ ascorbate oxidase in HEPEs buffer (pH 7.5) through the channel at $20 \mu \mathrm{l} / \mathrm{min}$ for $1 \mathrm{~h}$.

Fig. 4. a) The collected signals of AA analyzed by the enzyme-loaded microfluidic sensor and online UV/vis spectrophotometer, and b) plot of $-\Delta A$ versus the initial concentration of AA $\left(c_{0}\right)$. Different AA solutions in acetate buffer (50 mM, pH 5.6) were controlled to pass through the enzyme-loaded microfluidic channel at $5 \mu \mathrm{L} / \mathrm{min}$. The absorbance was averaged between the wavelength of 265 and $267 \mathrm{~nm}$. The concentrations are labeled on the top of curves in a) with the unit of $\mu \mathrm{M}$. Solid line in b) shows the linear regression fit $\left(\mathrm{r}^{2}=0.9658\right)$ of $-\Delta A$ to $c_{0}$. Arrows in a) indicate the time when it is started to sample the solution through the microfluidic channel. $A 0$ and $A^{\prime}$ are the absorbance before and after on-chip oxidation, respectively. $\triangle A$ : $A^{\prime}-A 0$.

\section{Scheme 1.}




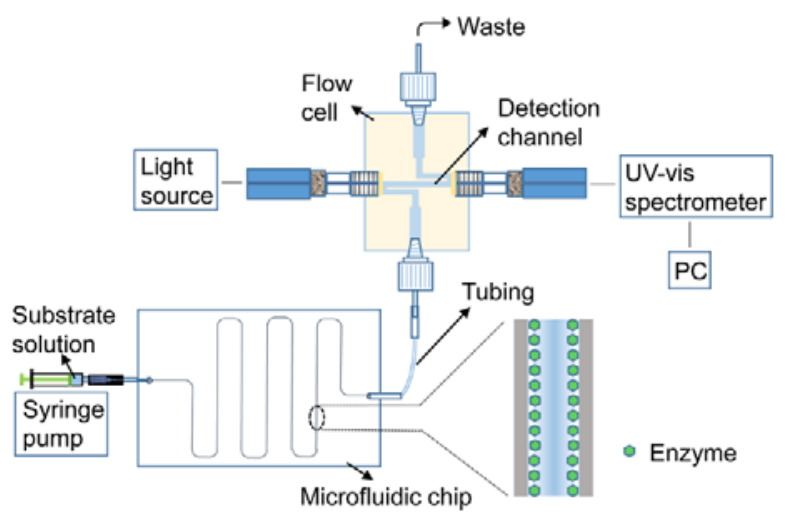

Scheme 1. Schematic illustration of the microfluidic sensor integrated with after-channel UV/vis spectrophotometric detection for food ingredient analysis. The microchannel is immobilized with enzymes to catalyze the consumption of target molecules. 
Fig. 1
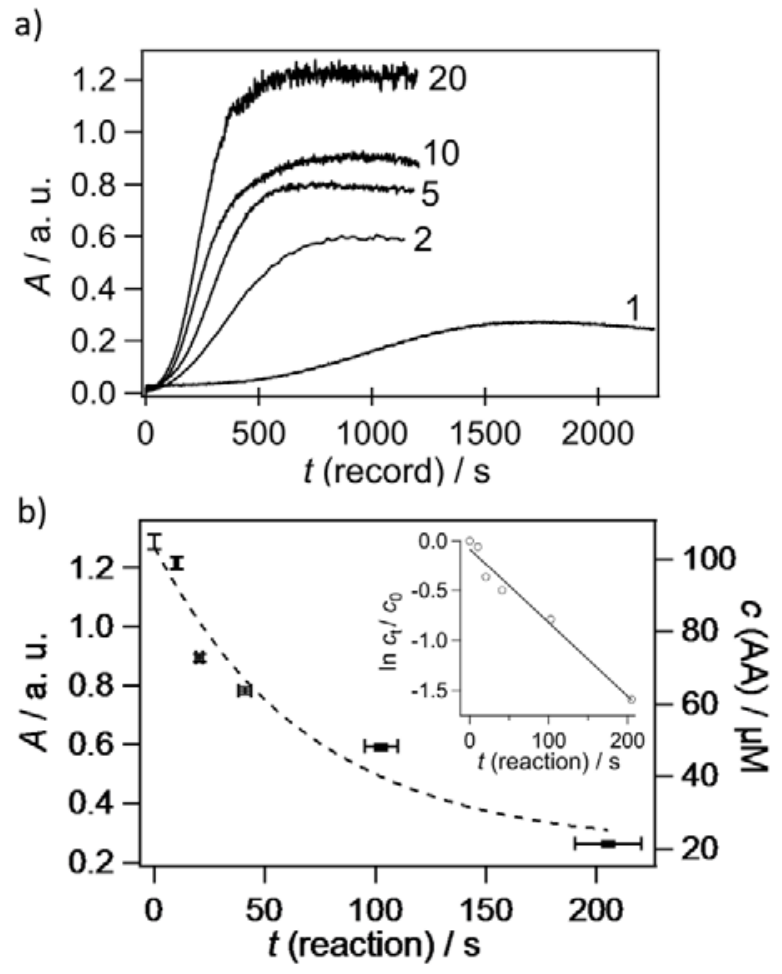

Fig. 1. a) A representative UV/vis absorbance signal of AA solution after passing through the microfluidic sensor under different flow rates (indicated besides each curve with the unit of $\mu \mathrm{L} / \mathrm{min}$ ). AA solution was freshly prepared with the initial concentration of $100 \mu \mathrm{M}$ in $50 \mathrm{mM} \mathrm{HAc} / \mathrm{NaAc}$ buffer (pH 5.6). The absorbance was averaged between the wavelength of 265 and $267 \mathrm{~nm}$. b) UV/vis absorbance at $266 \mathrm{~nm}$ and AA concentration change as a function of reaction time. Inset is the semi-logarithm plot of the concentration change (mean) of AA as a function of reaction time (mean). $c_{0}$ is the starting concentration of AA (100 $\left.\mu \mathrm{M}\right)$, and $c_{\mathrm{t}}$ is the concentration of $\mathrm{AA}$ at reaction time, $t$. 
Fig 2.

a)

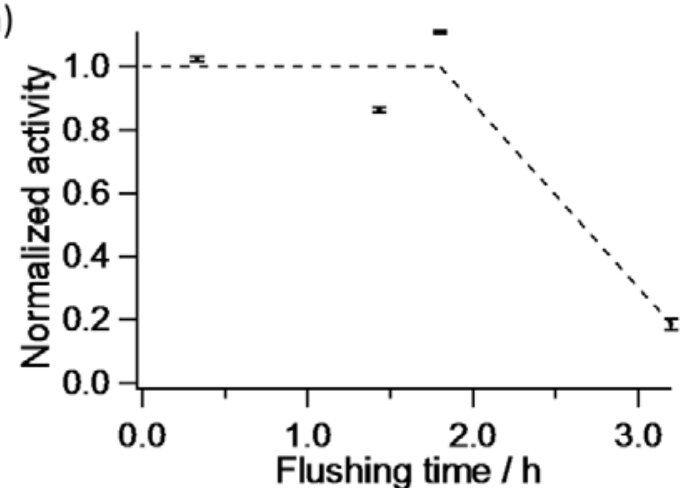

b)

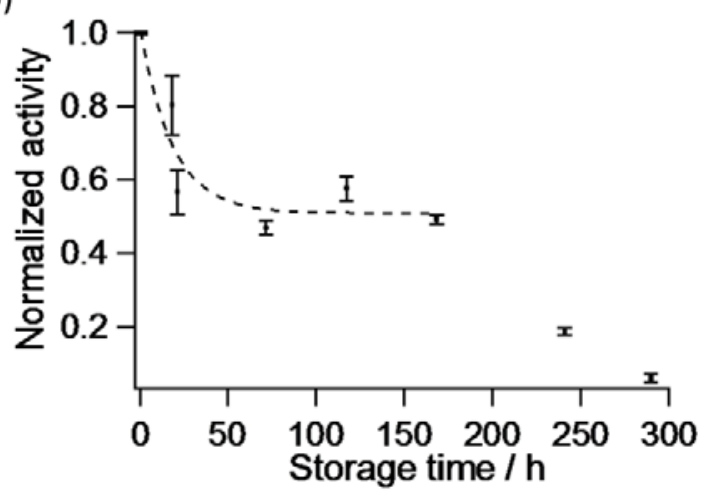

Fig. 2. Normalized activity of the enzyme-loaded PDMS microchip sensor to substrate after (a) different continuous flushing time by $50 \mathrm{mM}$ acetate buffer at $20 \mu \mathrm{L} / \mathrm{min}$, and (b) different storage time under $4{ }^{\circ} \mathrm{C}$. Error bar shows the standard deviation. The flow rate used to inject AA solution was $5 \mu \mathrm{L} / \mathrm{min}$. AA solution was freshly prepared in $50 \mathrm{mM}$ acetate buffer ( $\mathrm{pH}$ 5.6) with the initial concentration of $100 \mu \mathrm{M}$. Ascorbate oxidase was preloaded in the microfluidic channels by flowing $1 \mu \mathrm{g} / \mathrm{mL}$ ascorbate oxidase in $10 \mathrm{mM}$ HEPEs buffer through the channels at $20 \mu \mathrm{L} / \mathrm{min}$ for 1 hour. Dashed line is used to guide the view. 
Fig. 3.
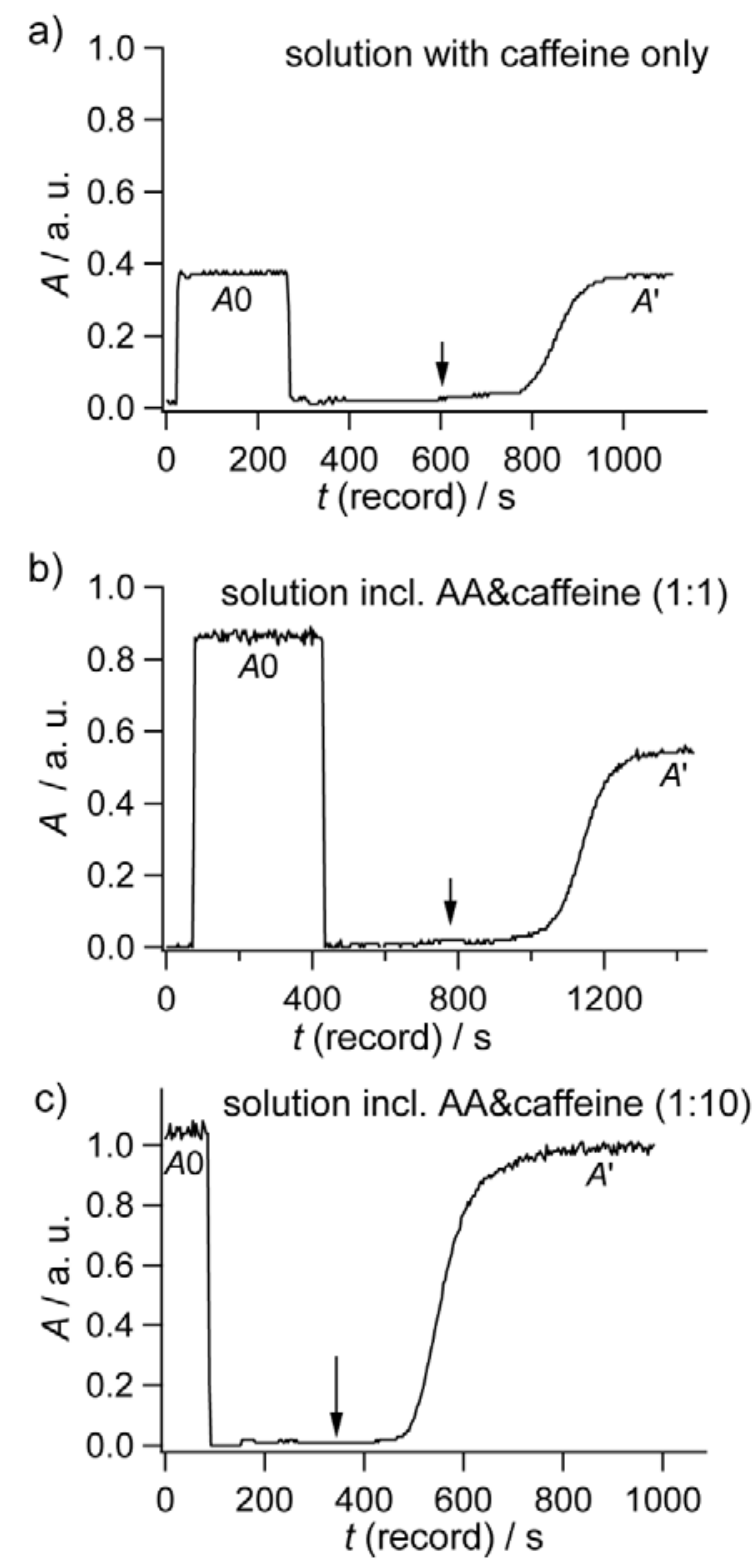

Fig. 3. Collected absorbance change at $266 \mathrm{~nm}$ of solutions containing a) only caffeine (37.5 $\mu \mathrm{M})$, b) AA and caffeine (37.5 $\mu \mathrm{M}$ each), and c) $10 \mu \mathrm{M}$ AA and $100 \mu \mathrm{M}$ caffeine, before (A0) and after ( $\mathrm{A}^{\prime}$ ) passing through the enzyme-loaded microfluidic sensor at $5 \mu \mathrm{L} / \mathrm{min}$. Arrows indicate the time when it is started to sample the solution through the microfluidic channel. The absorbance was averaged between the wavelength of 265 and $267 \mathrm{~nm}$. The used microfluidic channel was freshly prepared by flowing $2 \mu \mathrm{g} / \mathrm{mL}$ ascorbate oxidase in HEPEs buffer (pH 7.5) through the channel at $20 \mu \mathrm{l} / \mathrm{min}$ for $1 \mathrm{~h}$. 
Fig. 4.
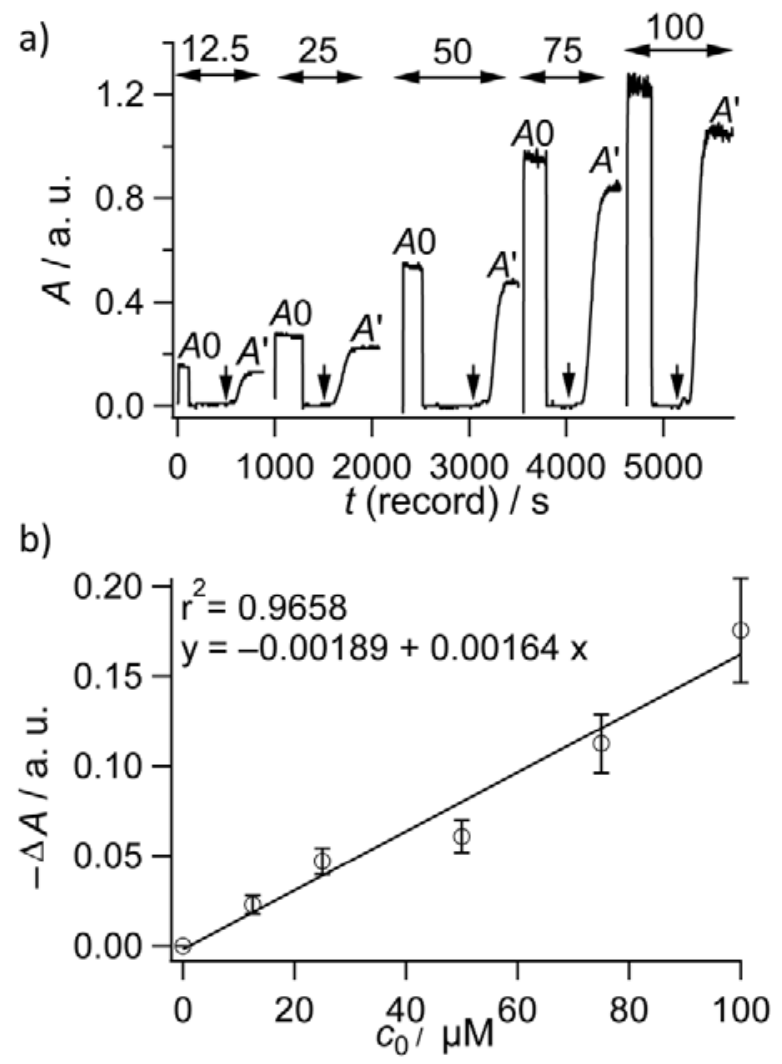

Fig. 4. a) The collected signals of AA analyzed by the enzyme-loaded microfluidic sensor and online UV/vis spectrophotometer, and b) plot of $\Delta A$ versus the initial concentration of AA $\left(c_{0}\right)$. Different AA solutions in acetate buffer (50 mM, pH 5.6) were controlled to pass through the enzyme-loaded microfluidic channel at $5 \mu \mathrm{L} / \mathrm{min}$. The absorbance was averaged between the wavelength of 265 and $267 \mathrm{~nm}$. The concentrations are labeled on the top of curves in a) with the unit of $\mu \mathrm{M}$. Solid line in b) shows the linear regression fit $\left(r^{2}=0.9658\right)$ of $\Delta A$ to $c_{0}$. Arrows in a) indicate the time when it is started to sample the solution through the microfluidic channel. $A 0$ and $A^{\prime}$ are the absorbance before and after on-chip oxidation, respectively. $\triangle A$ : $A^{\prime}-A 0$.

\section{Tables}

Table 1. Monitored UV/vis absorbance of AA solution (100 $\mu \mathrm{M}$ in $50 \mathrm{mM}$ acetate buffer (pH 5.6)) after flowing through three different enzyme-loaded microfluidic channels at $5 \mu \mathrm{L} / \mathrm{min}$. The microfluidic channels were 
independently prepared by flowing $1 \mu \mathrm{g} / \mathrm{mL}$ ascorbate oxidase in $10 \mathrm{mM}$ HEPEs buffer through the channels at 20 (channel 1), 10 (channel 2), and $5 \mu \mathrm{L} / \mathrm{min}$ (channel 3) for 1 hour, respectively.

\begin{tabular}{cc}
\hline Channel No. & $A /$ a. u. \\
1 & 0.7834 \\
2 & 0.6722 \\
3 & 0.7453 \\
Average & $0.7336 \pm 0.0565$ \\
RSD & $7.7 \%$ \\
\hline
\end{tabular}

Appendices for

\title{
Interference-Blind Microfluidic Sensor for
}

\section{Ascorbic Acid Determination by UV/vis Spectroscopy}

\author{
Hongyan $\mathrm{Bi}^{1, *}$, Ana Carolina Fernandes ${ }^{2,3}$, Susana Cardoso ${ }^{2}$, Paulo Freitas ${ }^{1,}$ \\ ${ }^{1}$ International Iberian Nanotechnology Laboratory (INL), Av. Mestre José Veiga, 4715-330 Braga, Portugal \\ ${ }^{2}$ INESC Microsistemas e Nanotecnologias (INESC MN), Rua Alves Redol, 9-1, 1000-029 Lisbon, Portugal \\ * Correspondence should be addressed to Hongyan Bi \\ Tel: + 351253140 112; Fax: +351253140119 \\ E-mail: hongyan.bi@inl.int \\ ${ }^{3}$ Present address: CAPEC-PROCESS, Technical University of Denmark, 2800 Kgs, Lyngby, Demark
}




\section{A: Mask design and a serpentine microfluidic chip}

As shown in Supplementary Fig. A. 1, a microfluidic chip patterned with running-track like structure was designed to increase the fluctuation of substrate in the microfluidic device. Fig. A. 1 c) shows the change of fluid, composed of 2 different colored dye solutions, inside the microfluidic channel. It can be observed that the laminar fluid in the microfluidic channel can be disturbed when then it passes through the running track like channel. Several tracks were designed to guarantee the fluctuation of substrate solution in the microfluidic channel even when very low flow rate was applied.
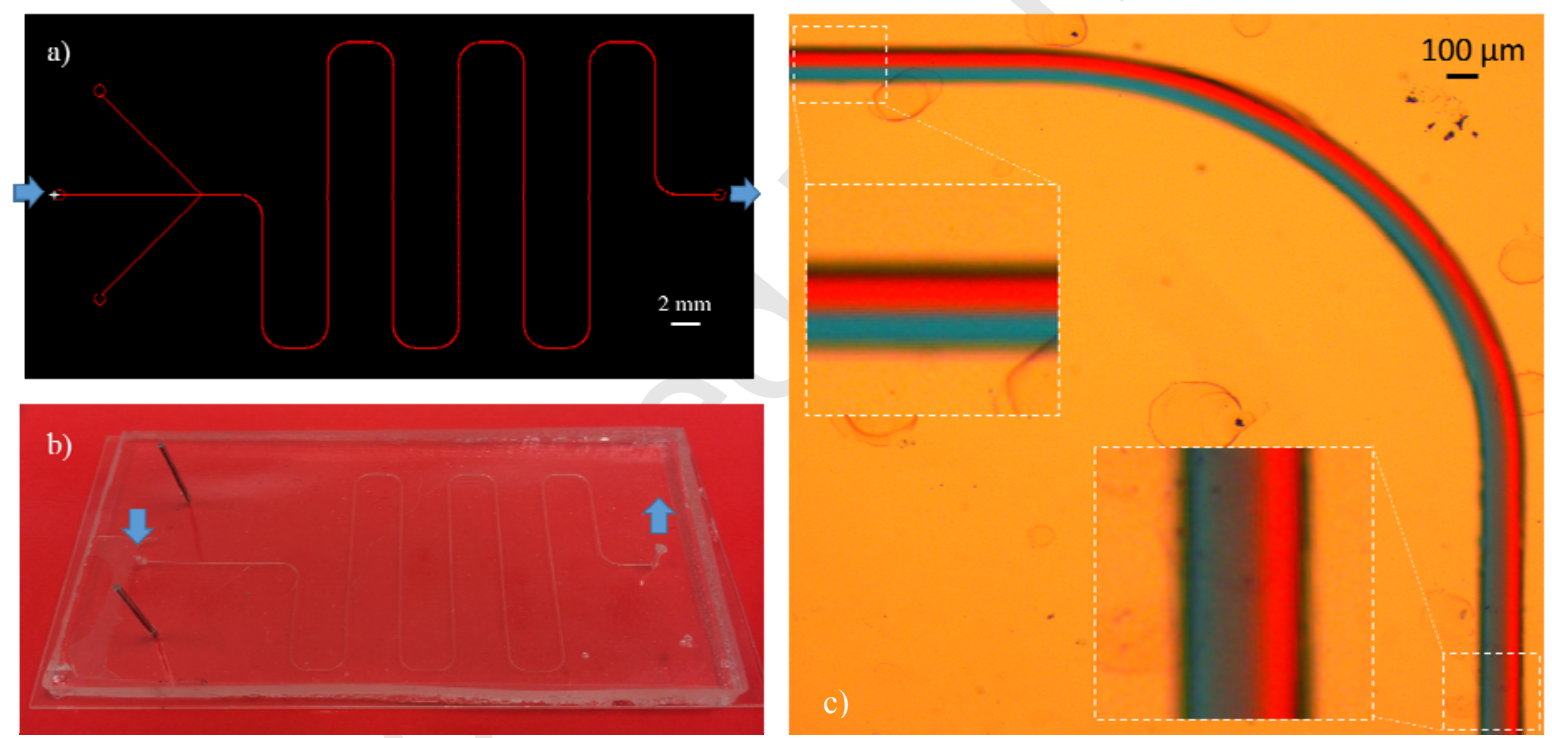

Fig. A. 1. Mask design a) and picture b) of the serpentine PDMS chip. The inlet and outlet reservoirs are indicated by blue arrows that also show the flow direction during experiments. The channel is $100 \mu \mathrm{m}$ in depth and $100 \mu \mathrm{m}$ in width; c) Microscopic picture of the disturbance of a laminar flow, composed of two colored dye solutions, when passing through the designed running-track like channel. Insets are the zoomed pictures. Injection flow rate is 75 $\mu \mathrm{L} / \mathrm{min}$. 


\section{B: UV/vis absorption of L-ascorbic acid and dehydroascorbic acid}

In order to quantify L-ascorbic acid (AA) by UV/vis absorbance signal, the molar attenuation coefficient of AA was measured. AA in $50 \mathrm{mM}$ of sodium acetate (NaAc) - acetic acid (HAc) buffer ( $\mathrm{pH}$ 5.6) displayed characteristic UV/vis spectrum with a maximum absorbance at $266 \mathrm{~nm}$. Fig. B. 1 a) shows the UV/vis absorption spectra of AA at different concentrations, and the plot of absorbance at $266 \mathrm{~nm}$ as a function of the concentration of AA. A good linearity is obtained with $r^{2}=0.9908$, which follows well the Beer-Lambert law in the applied concentration range. Linear regression analysis shows that the molar attenuation coefficient of AA in the used buffer solution is $(1.248 \pm 0.005) \times 10^{4} \mathrm{~L} \mathrm{~mol}^{-1} \mathrm{~cm}^{-1}$. Fig. B. $\left.1 \mathrm{~b}\right)$ compares the $\mathrm{UV} / \mathrm{vis}$ spectra of ascorbic acid and dehydroascorbic acid in $50 \mathrm{mM}$ of acetate buffer $(\mathrm{pH}$ 5.6), illustrating that dehydroascorbate has no absorbance at $266 \mathrm{~nm}$.
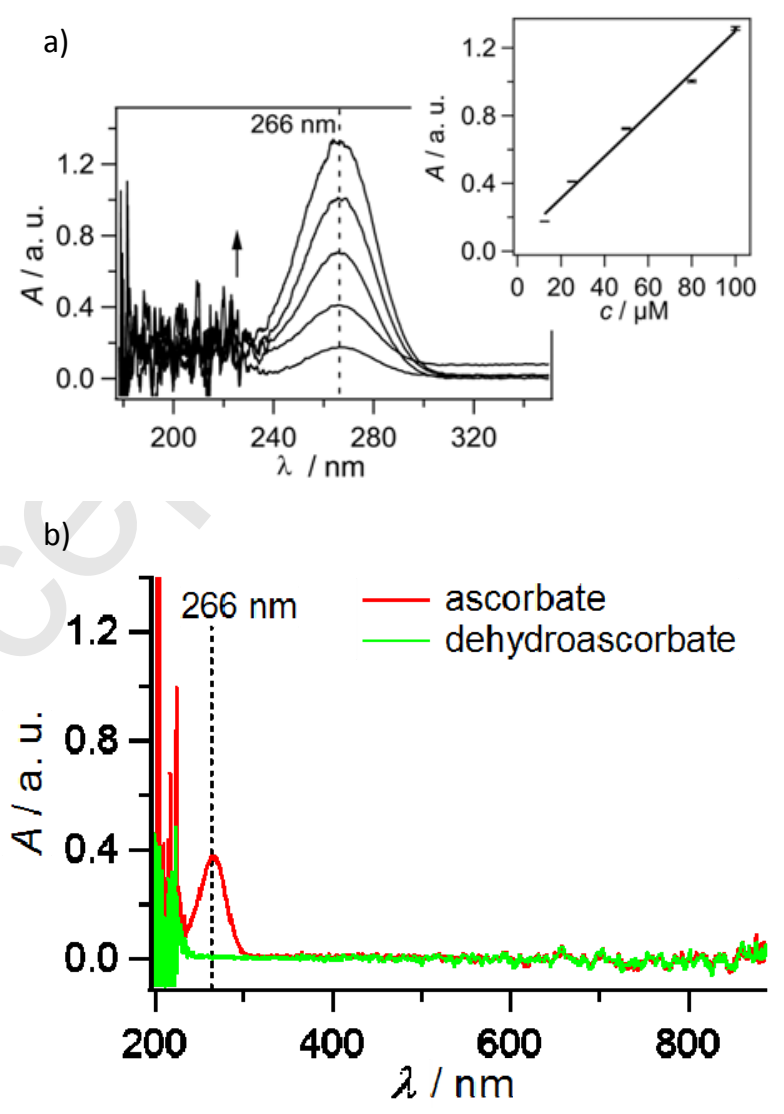
Fig. B. 1. a) UV/vis absorbance spectra of AA at different concentrations. The solution was prepared in $50 \mathrm{mM}$ acetate buffer ( $\mathrm{pH}$ 5.6). The concentrations were $12.5,25,50,80$ and $100 \mu \mathrm{M}$ respectively along the arrow indicated direction. Inset is the plot of UV/vis absorbance at $266 \mathrm{~nm}$ versus the concentration of AA. Error bar shows the obtained standard deviation. b) UV/vis spectra of ascorbic acid $(30 \mu \mathrm{M})$ in $50 \mathrm{mM} \mathrm{pH} 5.6$ buffer $(\mathrm{HAc} / \mathrm{NaOH})$ and dehydroascorbic acid $(30 \mu \mathrm{M})$ in the same aqueous solution. The UV/vis spectrophtotometric measurement was performed by Ocean Optics spectrophotometer connected with 4-way cuvette holder (CUV-ALL-UV, Ocean Optics) and an Eppendorf cuvette (Sigma-Aldrich). 


\section{C: The influence of after-channel volume of tubing on the response time of UV/vis spectroscopy}
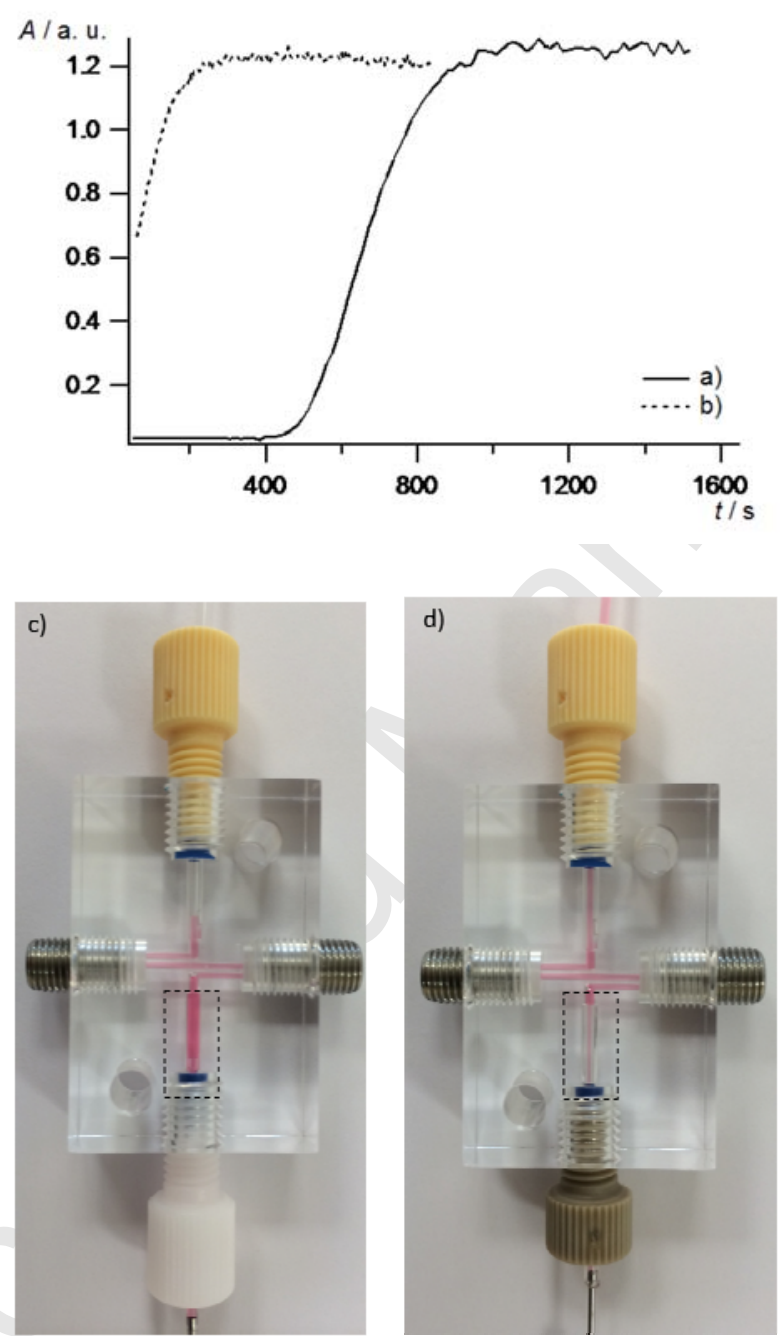

Fig. C. 1. UV/vis absorbance signals collected by UV/vis flow-cell with different after-channel dead volumes: a) under intrinsic after-channel volume of the flow-cell, b) after modifying the sampling part of the flow-cell by tubing with smaller volume. The corresponding pictures of the flow-cell are shown as c) and d), respectively. The modified part is highlighted by the dashed frame. In (a) and (b) $100 \mu \mathrm{M}$ ascorbic acid solution was sampled through the microfluidic channel with a flow rate of $5 \mu \mathrm{l} / \mathrm{min}$. Buffer: $50 \mathrm{mM} \mathrm{HAc} / \mathrm{NaAc}, \mathrm{pH} 5.6$. In (c) and (d), the filled red solution was diluted from alimentary liquid dye (Vahiné) to show the flow-cell channel. 


\section{D: UV/vis absorbance of caffeine and AA}

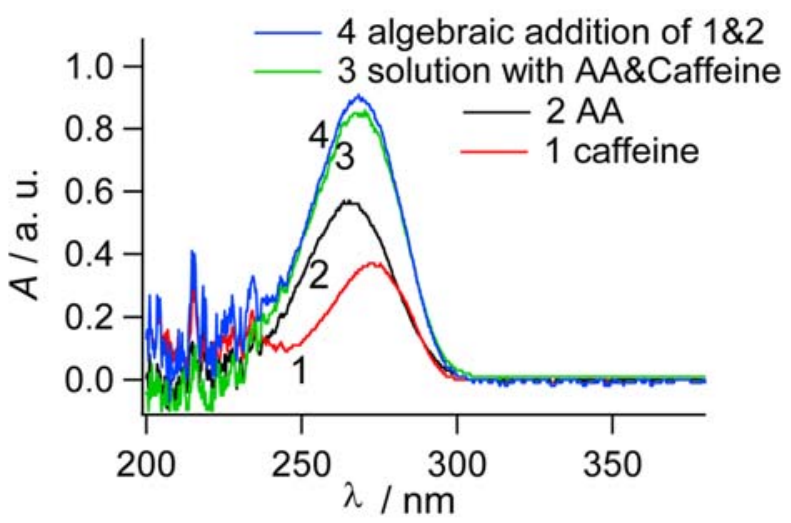

Fig. D. 1. UV/vis spectra of AA solution 1), caffeine solution 2), and the solution with both AA and caffeine 3). The concentration of AA and caffeine was $37.5 \mu \mathrm{M}$ in each case. 4) is the algebraic addition of 1) and 2). Caffeine solution was prepared with water. AA solution was prepared with acetate buffer $(50 \mathrm{mM}, \mathrm{pH} 5.6)$. UV/vis spectroscopic detection was performed with a disposable cuvette (Eppendorf Uvette, Hamburg, Germany).

Highlights:

- A microfluidic bio-sensor is developed for quantification of ascorbic acid;

- The established bio-sensor is blind to interference;

- The strategy is technically easy and relies on simple instrumental procedure;

- The principle can be duplicated for the detection of other dietary ingredients;

- The developed strategy is promising to be widely spread in food industry. 
